\title{
Uso de dispositivos de micronebulización en adultos mayores en un programa de hospitalización domiciliaria
}

\author{
Karen C'ayw'ce Panche Castellanos ${ }^{1}$, Lina Rangel Acosta ${ }^{1}$, \\ Lucia Constanza Corrales Ramírez ${ }^{2}$ \\ 1. Estudiantes Programa Bacteriología y Laboratorio Clínico. \\ Semillero de Investigación Anakalipse, Grupo de Investigación Ceparium. \\ Universidad Colegio Mayor de Cundinamarca, Bogotá, Colombia. \\ 2. Docente investigadora, Grupo de Investigación Ceparium. \\ Universidad Colegio Mayor de Cundinamarca, Bogotá, Colombia.
}

Correspondencia:1corrales@unicolmayor.edu.co

Recibido: 03/05/2013 Aceptado: 20/08/2013

\begin{abstract}
Resumen
La atención médica domiciliaria es una estrategia que permite evitar infecciones asociadas al cuidado de la salud en individuos con deficiencias inmunológicas como los adultos mayores. Se realizó una investigación de tipo descriptivo-longitudinal, en la que se tuvieron en cuenta condiciones relacionadas con el dispositivo de micronebulización como: el tiempo de uso, el lavado del dispositivo y su almacenamiento. Con respecto al terapeuta se tuvo en cuenta: lavado de manos y aplicación del protocolo de limpieza y desinfección. Se realizaron dos tomas de muestra a diecisiete dispositivos de micronebulización individual de adultos mayores pertenecientes al programa de hospitalización domiciliaria de Forja Empresas Ltda, a los quince y treinta días de uso después de la entrega del dispositivo en dos momentos: antes y después del procedimiento de la terapia respiratoria.
\end{abstract}

Se identificaron ocho microorganismos en la primera toma de muestra que se clasificaron como flora transitoria y diecinueve microorganismos en la segunda, en la que se encontró flora residente, transitoria y potencialmente patógena. En relación al protocolo de limpieza y desinfección, realizado por los terapeutas, se observó modificaciones al protocolo establecido por Forja Empresas Ltda, sin embargo dicho protocolo no incluye el lavado de manos, punto indispensable para la atención del paciente. Se hace necesario brindarles información oportuna a los pacientes, familiares y/o cuidadores sobre el almacenamiento adecuado del dispositivo con el fin de evitar presencia de microorganismos que pueden afectar la salud de los adultos mayores.

Palabras clave: adulto mayor, contaminación de equipos, infecciones oportunistas, servicios de atención de salud a domicilio. 


\title{
Use of micro-nebulization equipment devices in older adults in an inpatient program home
}

\begin{abstract}
Home health care is a strategy that allows avoiding infections associated with health care of individuals with immune deficiencies such as older adults. A descriptive-longitudinal investigation was conducted, which took into account conditions related to the micro-nebulization equipment device such as: its time of use, cleansing, and storage. With respect to the therapist, it was taken into account: hand washing and implementation of the protocol of cleaning and disinfection. Two different samples were taken to seventeen individual micro-nebulization equipment devices of older adults belonging to the program of home hospitalization of Forging Companies Ltd., after fifteen and thirty days of use after the delivery of the device in two times: before and after the respiratory procedure.
\end{abstract}

Eight microorganisms were identified in the first portion of the sample that were classified as transitory flora and nineteen microorganisms in the second one, where resident, transient, and potentially pathogenic flora was found. In relation to the protocol of cleaning and disinfection carried out by the therapists. Changes to the protocol established by Forging Companies Ltd. were observed; however, this protocol does not include the washing of hands, which is a vital point for patient care. It is necessary to provide patients, family members and/or caregivers with timely information about the proper storage of the device in order to avoid the presence of microorganisms that can affect the health of older adults.

Key Words: equipment contamination, home health care services, older adult, opportunistic infections.

\section{Introducción}

Con el propósito de descongestionar los servicios de salud y evitar infecciones nosocomiales, se establece la atención especializada domiciliaria para pacientes con deficiencias en el sistema inmune, como las que afectan al adulto mayor. A nivel internacional, la Sociedad Espańola de Neumología y Cirugía Torácica (SEPAR), contempla protocolos estandarizados para los procedimientos médicos integrales en casa, específicamente para el adulto mayor y las diversas patologías pulmonares, así como guías y recomendaciones para disminuir los riesgos asociados a la atención médica en el domicilio $(1,2)$.

En Latinoamérica, investigaciones realizadas en Brasil describen y analizan, específicamentelos dispositivos médicos asociados a los procedimientos de nebulización, y caracterizan la microbiota asociada que pudiera causar sobreinfecciones a individuos con patologías como fibrosis quística, concluyendo, a partir de los resultados, que en una muestra de pacientes, a pesar de las técnicas de desinfección inadecuadas, los nebulizadores no son una fuente de contaminación microbiana (3), sin embargo, otras investigaciones, en las cuales se realizó comparación de la microbiota de los dispositivos de nebulización, en ambiente hospitalario y domiciliario, indica que los nebulizadores independientemente al contexto, son posibles vías de transmisión de agentes patógenos asociados a infecciones con resistencia a los antimicrobianos, por tanto plantean hacer énfasis en la higiene de los dispositivos como factor importante de prevención $(4,5)$. 
Las condiciones donde se realizan los procedimientos domiciliarios tienen sus características y dinámicas propias, por ello es necesario correlacionar dichos aspectos con el ambiente microbiológico. A nivel nacional, si bien existen investigaciones de tipo analítico y descriptivo de variables como contaminación de dispositivos biomédicos y aplicación de protocolos de limpieza y desinfección en unidades de cuidados intensivos y dispositivos invasivos $(6,7)$, no se cuenta con evidencia de estudios relacionados que se puedan tomar como referencia sobre cuáles son los microorganismos que se encuentran en los dispositivos de micronebulización usados en terapias respiratorias domiciliarias y representen un riesgo para los pacientes con estas particularidades. Tampoco hay una relación establecida con el tiempo adecuado para el uso de dispositivos empleados en los tratamientos respiratorios de la población de la tercera edad.

La atención a este grupo etario se hace relevante debido a que, según estadísticas del DANE, para el año 2005, la ciudad de Bogotá contaba con 564.260 ancianos entre 60 y 115 ańos, estimaciones realizadas por esta misma entidad muestran que para el año 2012 son 779.534 los adultos mayores con un rango de edad entre 60 a 100 ańos y que para el año 2020 serán 1.153.194 (8). Con base en las estimaciones de crecimiento de población del adulto mayor, y de la esperanza de vida, se hace necesario establecer medidas efectivas para garantizar la calidad de vida, dado que en esta etapa de la vida el sistema inmunitario sufre un declive natural que hace que se tenga una población más vulnerable frente a su estado de salud y posibles patologías de base a las que se padecían con anterioridad.

La creciente modalidad de atención domiciliaria, como opción de recuperación con beneficios documentados que mejoran la calidad de vida en la dimensión emocional, interacción social, estado de alerta y comunicación, además relación positiva referida en costo-efectividad, hace necesario el monitoreo y control de las condiciones en el hogar que puedan ser un foco de contaminación como aseo del área de vivienda y hábitos higiénicos de quienes están al cuidado del enfermo, entre otros aspectos, con el fin de mejorar y fortalecer el ambiente que proteja la salud y evite infecciones tanto al paciente como a su grupo familiar, como lo concluyen estudios realizados por Espinel et al. (9) en México y Gamboa en Colombia (10).

El apoyo de un profesional idóneo es importante, siendo necesaria la consciencia y conocimiento en el manejo de dispositivos médicos usados para tratar diferentes patologías. En el caso de enfermedades respiratorias, donde el tratamiento de elección se relaciona con sesiones de terapia domiciliaria, se hace imprescindible el lavado del material utilizado en éstas, pero también un tiempo de uso coherente de acuerdo con la situación médica del paciente y tiempo de vida útil de los diferentes dispositivos. También es necesario el monitoreo de técnicas e insumos que permitan garantizar procesos eficientes y eficaces que mejoren la condición clínica en el ambiente domiciliario, de tal manera que los procesos realizados en el domicilio no sean desfavorables para los pacientes y tampoco para los habitantes del hogar en situación de vulnerabilidad.

Los pacientes que hacen parte del estudio son usuarios de Forja Empresas Ltda, la cual provee servicios de atención médica integral, servicios terapéuticos y cuidados paliativos en el domicilio, son intermediarios de diferentes Entidades Prestadoras de Salud (EPS) y regímenes de medicina prepagada. Para el caso particular, los pacientes que presentan afección respiratoria son atendidos dependiendo del nivel de gravedad y con base en ello se observa que reciben el tratamiento de terapias con frecuencias que pueden variar desde una diaria, dos, tres y hasta todos los días de la semana. Sin embargo, el procedimiento frente al manejo de los equipos es el mismo para todos los pacientes, independiente de la frecuencia de las terapias y patologías de base que éstos presenten.

En este caso los dispositivos de micronebulización para las terapias respiratorias son entregados 
a cada uno de los pacientes una vez al mes y son cambiados después de 30 días o antes de finalizar este tiempo si el paciente presenta un cuadro de neumonía. El uso frecuente del equipo, el tiempo propuesto de vida útil (treinta días), el mantenimiento en condiciones no adecuadas y asépticas posibilitan la sobreinfección por bacterias de tipo endógeno o exógeno al paciente y que puede agravar la situación clínica del mismo.

Los pacientes usuarios del servicio de terapia respiratoria integrantes de la investigación fueron seleccionados teniendo en cuenta criterios de inclusión y de exclusión. Se empleó un diseño metodológico de tipo descriptivo de corte horizontal, donde se realiza toma de muestra de los dispositivos de micronebulización dos veces durante un mes, antes del procedimiento de terapia nebulizada y después del uso del dispositivo previo lavado y desinfección, con el fin de realizar aislamiento y clasificación según tipo de flora microbiana encontrada en los dispositivos usados durante el mes, de tal manera que se pudiera evaluar los factores que influyen en el uso y mantenimiento adecuado de estos equipos para evitar riesgos de sobre infección en los pacientes, teniendo en cuenta variables como el protocolo de limpieza y desinfección, condiciones de aseo del entorno del paciente, conocimiento del mantenimiento y uso de los implementos para las terapias respiratorias por parte de los cuidadores.

\section{Materiales y métodos}

El estudio describe los microorganismos hallados en las tomas de muestra realizadas: la primera, antes de llevarse a cabo la terapia respiratoria, y la segunda, después del procedimiento de lavado y desinfección una vez realizada la terapia; con el fin de determinar variables de riesgo asociadas al procedimiento de limpieza, desinfección y mantenimiento que podrían llevar a sobreinfección en adultos mayores hospitalizados en el domicilio. Este estudio es de corte longitudinal, debido a que se tomaron dos muestras en diferentes puntos del tiempo del uso del dispositivo de micronebulización por cada uno de los pacientes.

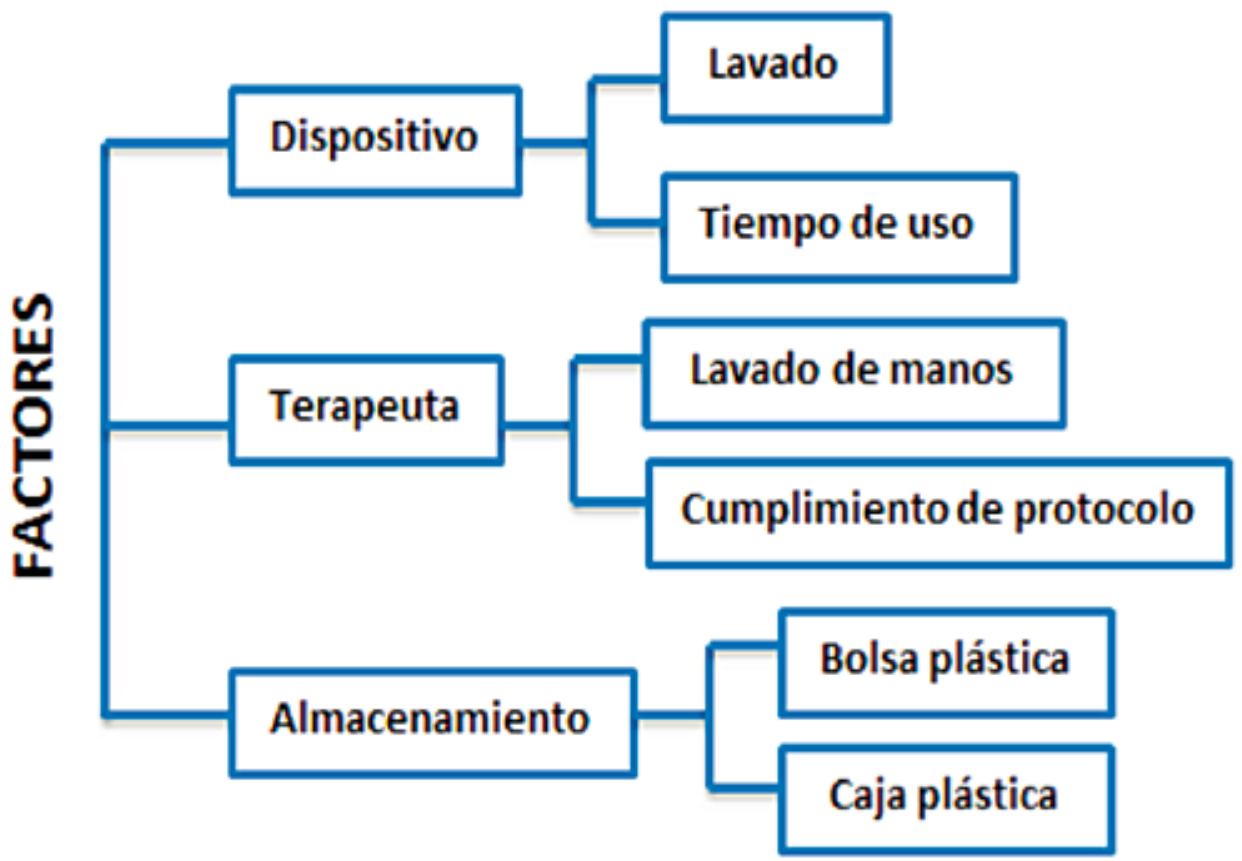

Grafica 1. Factores seleccionados en el estudio 
Los pacientes fueron seleccionados de acuerdo a los siguientes criterios de inclusión:

- Edades: entre 60 y 105 años.

- Atención domiciliaria con una frecuencia mínima de dos terapias a la semana (8 terapias respiratorias mensuales).

- Pacientes sin traqueotomía.

- Domicilio en Bogotá.

La muestra final se constituyó por 17 dispositivos de micronebulización.

\section{Primera fase: encuestas a pacientes $y$ terapeutas}

Previa visita al domicilio de los pacientes, se entregó el dispositivo de micronebulización para ser usado durante los 30 días, así mismo se socializó con los pacientes, familiares y/o cuidadores el cronograma de toma de muestra y se realizó el diligenciamiento de un cuestionario. La toma de muestra se hizo durante la sesión de terapia respiratoria del paciente en dos momentos durante el mes, en los cuales se realizó observación del cumplimiento del protocolo de limpieza, desinfección y almacenamiento de los dispositivos antes y después de su uso en la terapia.

Según las normas éticas de la Declaración de Helsinki y la resolución 8430 de 1993 del Ministerio de Salud (actual Ministerio de la Protección Social), la investigación no presenta riesgo para los seres humanos. Se tuvo especial cuidado en garantizar la confidencialidad de los datos, se informó a cada uno de los participantes la intencionalidad, los procedimientos y objetivos se consignaron en un consentimiento informado que firmó el usuario del dispositivo o su cuidador.

Se aplicaron encuestas a terapeutas y pacientes, familiares y/o cuidadores para evaluar el grado de información sobre el cuidado de los implementos usados en los procedimientos y el cumplimiento de protocolos de desinfección de acuerdo a las indicaciones estandarizadas por parte de Forja Empresas Ltda, para los dispositivos de nebulización, para conocer aspectos relacionados con estilo de vida y condiciones propias del paciente y de su entorno; información respecto a procedimientos de terapia nebulizada e implementos usados en esta, protocolo de limpieza, desinfección y almacenamiento del dispositivo de micronebulización.

A los terapeutas se les indagó además sobre el tiempo de experiencia laboral dentro de la empresa y uso de barreras de bioseguridad.

\section{Segunda fase: recolección de muestras}

La frecuencia de toma de muestra para cada paciente obedeció al siguiente esquema:

\section{Entrega dispositivo}

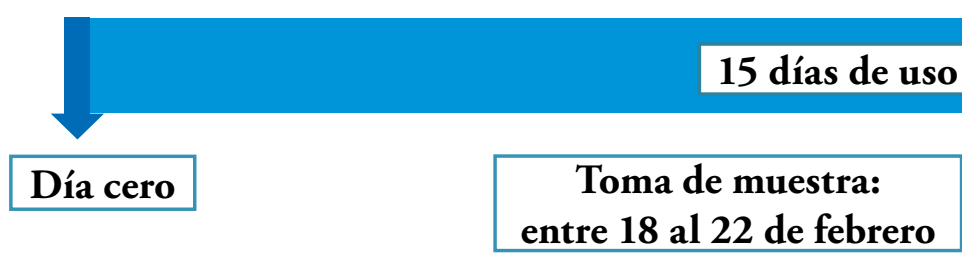

Fin de uso dispositivo

Grafico 2. Cronograma de toma de muestra a los dispositivos de micronebulización individual en el estudio: factores que influyen en el uso de dispositivos de micronebulización en adultos mayores del programa hospitalización domiciliaria. Forja Empresas Ltda. 
La toma de muestra se realizó de acuerdo con el protocolo de bioseguridad establecido.

1. Antes de iniciar el procedimiento de terapia, con un escobillón estéril, humedecido en solución salina $0.85 \%$ estéril, se toma la muestra rotándolo sobre sí mismo y recorriendo la superficie inferior de la careta del dispositivo de micronebulización del paciente. Se inocula en medio Stuart, según protocolo de la Secretaria Distrital de Salud para toma de muestras de superficies inertes (11). Finalizado el procedimiento y lavado el dispositivo de micronebulización se realiza una segunda toma de muestra de acuerdo al procedimiento establecido anteriormente.

2. Transporte de muestras en nevera de icopor en condiciones de refrigeración.

3. Siembra por agotamiento mediante procedimiento de cultivo ciego (agar sangre, Agar chocolate y Agar Mac Conkey). Incubación de cultivos en Agar sangre y Agar Mac Conkey a $37^{\circ} \mathrm{C}$ por 18 a 24 horas en aerobiosis, Agar chocolate incubación con atmósfera con 5\% de $\mathrm{CO}_{2}$, en condiciones de igual temperatura y tiempo.

4. Caracterización macroscópica y microscópica de los cultivos resultantes.

5. Identificación de género y especie de los microorganismos aislados, mediante técnicas semiautomatizadas (BBL CRYSTAL ${ }^{\circ}$ )según especificaciones del fabricante. Para la identificación del hongo levaduriforme resultante en la segunda toma de muestras se utilizó, el Equipo VITEK, versión VITEK 2 Systems: 05.04.

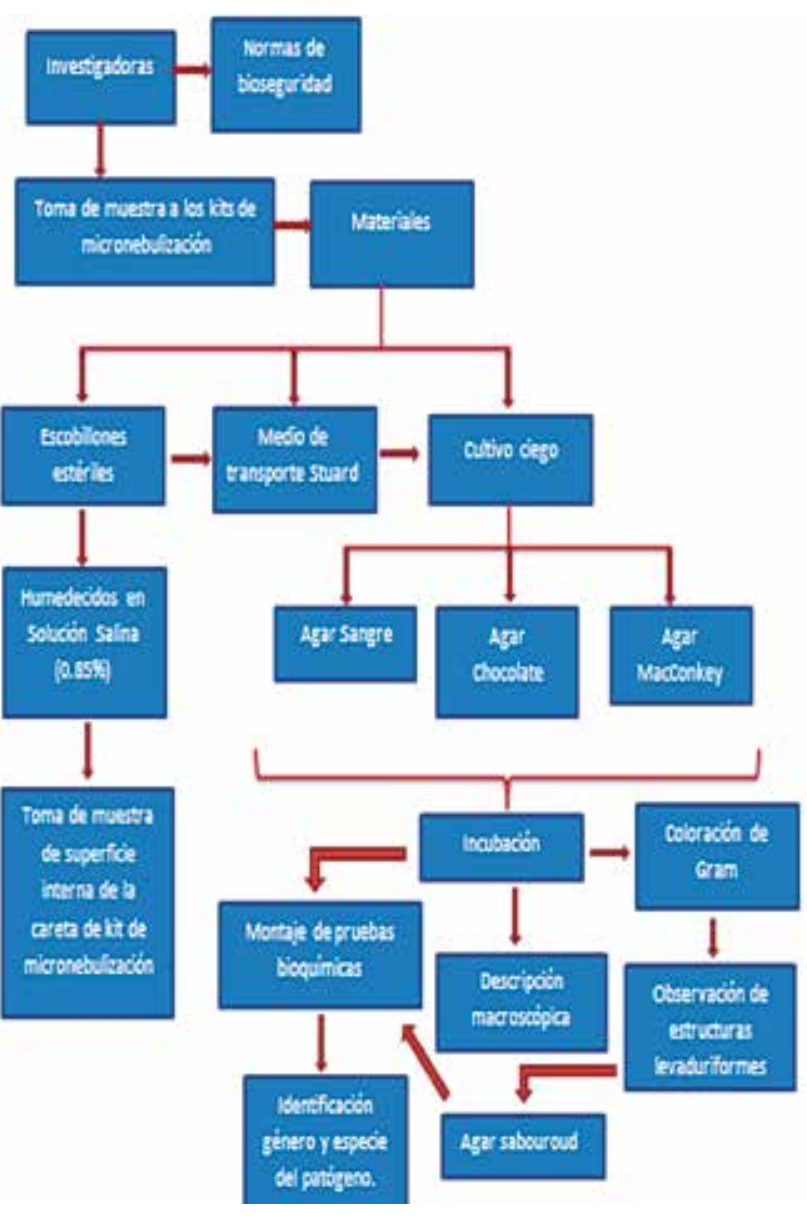

Grafico 3. Protocolo para la identificación de microorganismos desarrollado en el estudio: Factores que influyen en el uso de dispositivos de micronebulización en adultos mayores del programa hospitalización domiciliaria. Forja Empresas Ltda.

\section{Tercera fase: análisis estadístico}

El análisis estadístico se realizó mediante la construcción de una base de datos a partir de las encuestas realizadas, los microorganismos aislados y algunas condiciones fisiológicas y de vivienda de los pacientes en Microsoft Excel 2010 y empleando la herramienta "Tablas Dinámicas". Se ordenó la información para realizar análisis de 2 y 3 variables, se obtuvo la frecuencia relativa y absoluta y se realizaron diagramas de barras que representaran los hallazgos. 


\section{Resultados}

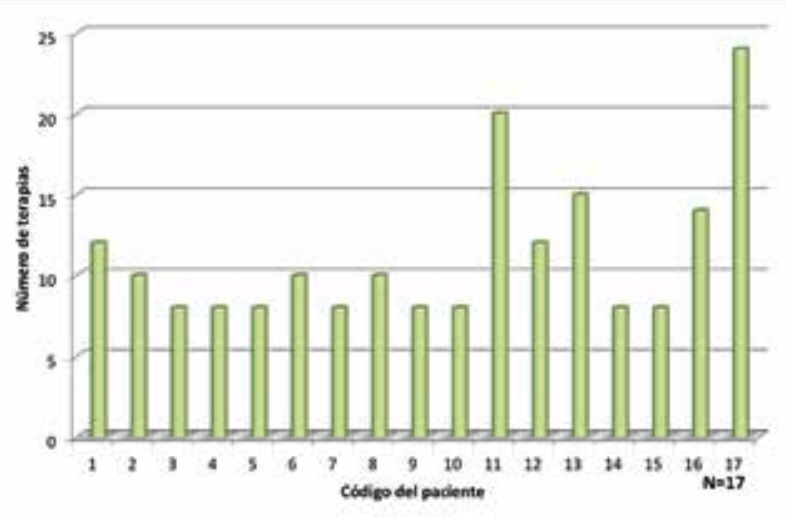

Gráfica 4. Distribución de frecuencia de las terapias respiratorias mensuales de los pacientes participantes

Con relación a la distribución de la frecuencia de terapias respiratorias mensuales con relación al número de pacientes, se observa que el $41,2 \%$ de los pacientes tiene una frecuencia de 8 terapias, el $23,5 \%$ de 10 terapias, el $11,7 \%$ de 12 terapias; el $23,2 \%$ de los pacientes tienen una frecuencia de $14,15,20$ y 24 terapias mensuales lo cual equivale al 5,8\% del total de los pacientes por cada una.

\section{Resultados a partir de las encuestas}

Con el fin de indagar y evaluar los conocimientos generales de los pacientes, familiares, cuidadores y terapeutas pertenecientes al programa de hospitalización domiciliaria de Forja Empresas Ltda, acerca del manejo, cuidado y desinfección de los dispositivos de micronebulización, así como algunos aspectos relacionados con las condiciones del paciente, se practicaron encuestas para cada grupo.

\section{Encuesta a pacientes, familiares o cuidadores} La encuesta para pacientes, familiares o cuidadores hace énfasis en las condiciones básicas de los pacientes, el conocimiento sobre el procedimiento de la terapia y del uso de los dispositivos de micronebulización.

\section{Protección del dispositivo}

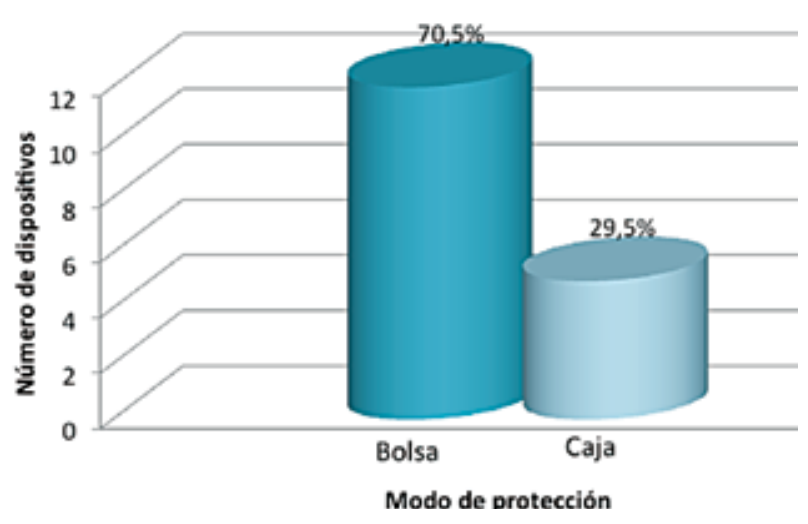

Gráfica 5. Protección del dispositivo de micronebulización

De acuerdo al modo de protección de los dispositivos se observó que el 70,5\% de estos son protegidos mediante el uso de bolsa plástica, mientras que el 29,5\% restante usan como forma de protección caja plástica.

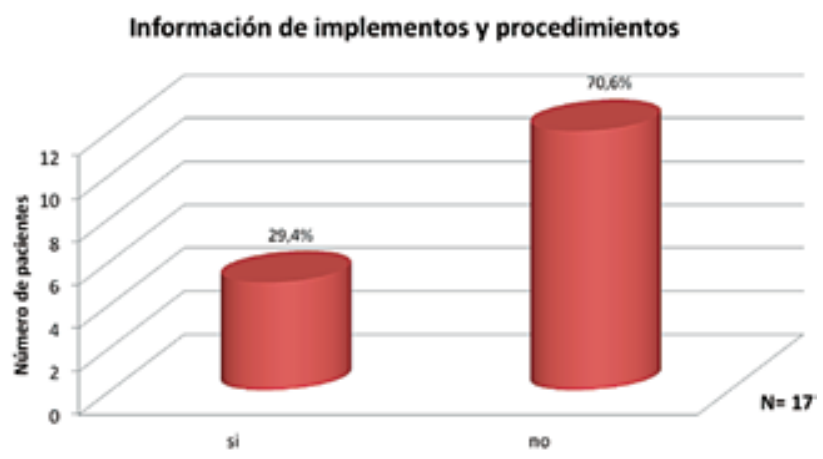

Gráfica 6. Información de pacientes, familiares y/o cuidadores de implementos y procedimientos relacionados con la terapia respiratoria

Al indagar con los pacientes, familiares y/o cuidadores si conocían o tenían información acerca de los implementos utilizados en la terapia respiratoria y el modo de uso de los mismos se encontró que el 29,4\% tienen algún conocimiento frente al procedimiento de la terapia y el uso de los dispositivos, sin embargo el 70,6\% restante indica que no tienen conocimiento de los implementos y procedimientos. 


\section{Encuesta a terapeutas}

En la encuesta que se aplicó a los terapeutas (ocho), que atendían a los 17 pacientes, se indagó sobre los conocimientos acerca del procedimiento de terapia respiratoria y el uso adecuado del dispositivo de micronebulización. Al verificar sobre el protocolo que realizan cada uno de los terapeutas en el procedimiento de la terapia respiratoria se obtuvo que el $100 \%$ de ellos cumplen con el lavado de manos con abundante agua de la llave y con relación al uso del jabón se encuentran diferentes respuestas: algunos usan el jabón disponible en la casa del paciente sea en barra o líquido, otros no usan jabón, y otros después del lavado con abundante agua utilizan gel antibacterial.

En relación con el uso de tapabocas, el 100\% de los terapeutas utilizan esta barrera de protección. Al verificar el cumplimiento del protocolo establecido para limpieza y desinfección de los dispositivos, el $25 \%$ de los terapeutas, es decir 2 cumplen con este protocolo.

Se solicitó que describieran el proceso de desinfección que se le realizaba al dispositivo de micronebulización a lo cual, un terapeuta indicó que no se realizaba ningún tipo de desinfección y solo utilizaba agua, otro terapeuta indicó que usa en el proceso gel antibacterial y/o gasas húmedas. Otro terapeuta indicó que una vez al mes el dispositivo de micronebulización es puesto durante 20 minutos en una mezcla de cloro (hipoclorito de sodio) con agua, con el fin de que se elimine la suciedad. Los demás terapeutas realizan el proceso de limpieza y desinfección con agua y jabón, puede ser en barra o líquido dependiendo de la disponibilidad de este en la casa del paciente. Dos de los terapeutas emplean jabón quirúrgico que suministra Forja Empresas Ltda.

\section{Resultados a partir de las muestras tomadas de los dispositivos de micronebulización}

La toma de muestra se realizó a las caretas y conductos que conforman el dispositivo de micronebulización, en momentos definidos según la planificación entre febrero y marzo de 2013.

Gráfica 4. Resultados de cultivo microbiológico en los dos momentos de toma de muestra

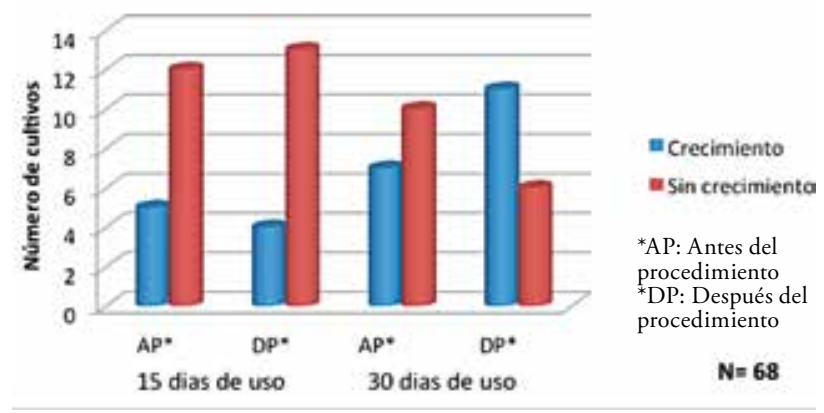

Con respecto al número de microorganismos aislados a partir de los dispositivos de micronebulización y el tiempo de uso: se observa un mayor número de aislamientos a los 30 días de uso, frente al primer aislamiento realizado a los 15 días.

Gráfica 5. Relación de microorganismos aislados del dispositivo de micronebulización a partir de la toma de muestra a los 15 días antes y después de su uso

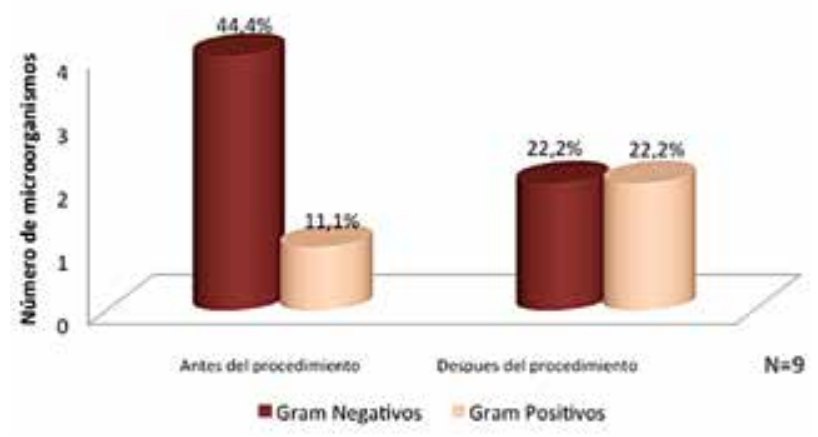

En la toma de muestra a los 15 días de uso, presentó un aislamiento bacteriano total de 9 microorganismos. Antes del uso del dispositivo en la terapia respiratoria con el paciente, se evidenció que el $44,4 \%$ de los microorganismos identificados 
corresponden a Gram negativos y el 11,1\% a Gram positivos. Después del uso del dispositivo se presentó un 22,2\% de microorganismos Gram negativos y Gram positivos.

Gráfica 6. Microorganismos aislados del dispositivo de micronebulización a partir de la toma de muestra a los 30 días antes y después de su uso

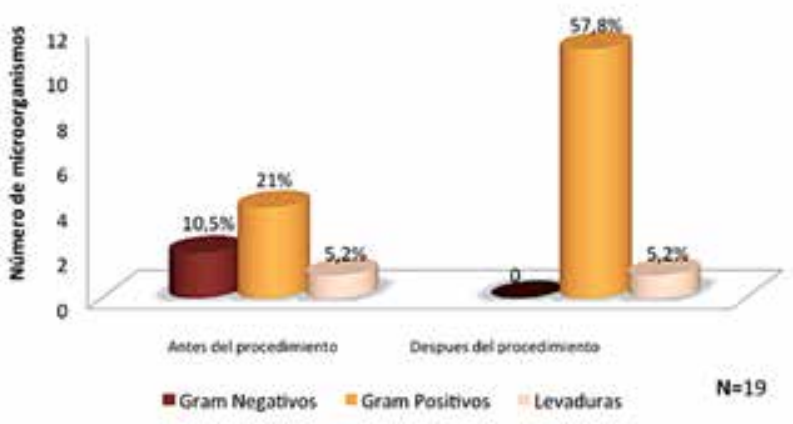

Después de los 30 días de uso los dispositivos, se presentó crecimiento en 12 dispositivos, en los cuales se identificaron 19 microorganismos de la siguiente manera: antes del uso del dispositivo en la terapia con el paciente el $10,5 \%$ corresponden a Gram negativos, el 21\% a Gram positivos y el $5,2 \%$ a levaduras. Después del uso del dispositivo en la terapia se presentó que el $57,8 \%$ de estos microorganismos pertenecen a Gram positivos y un $5,2 \%$ a levaduras.

Gráfica 7. Microorganismos identificados del dispositivo en relación con el tiempo

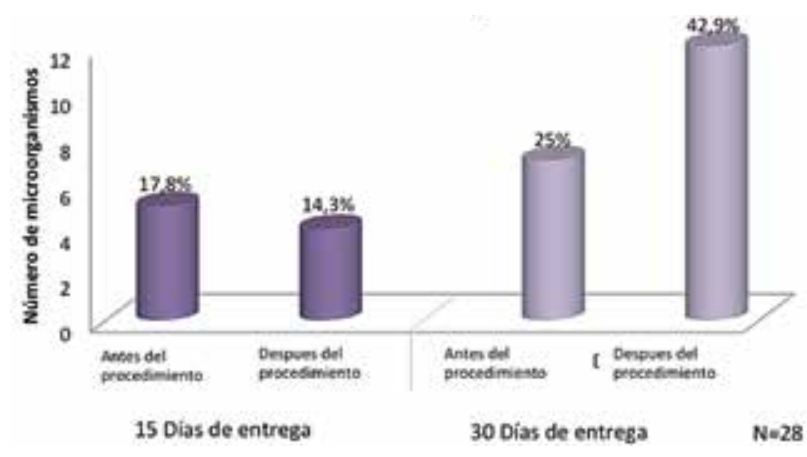

Durante el estudio se aisló e identificó un total de 28 microorganismos, que relacionados con el tiempo de uso, se observa que el $32.1 \%$ se aisló a los 15 días de uso del dispositivo, de los cuales el 17,8\% fueron aislados antes del uso y el 14,3\% después del uso. Treinta días después del uso se aislaron un $67.9 \%$ del total de los microorganismos, el 25\% corresponde a antes del uso y el $42.9 \%$ después de su uso.

Gráfica 8. Relación entre el número de terapias mensuales con el número de microorganismos identificados

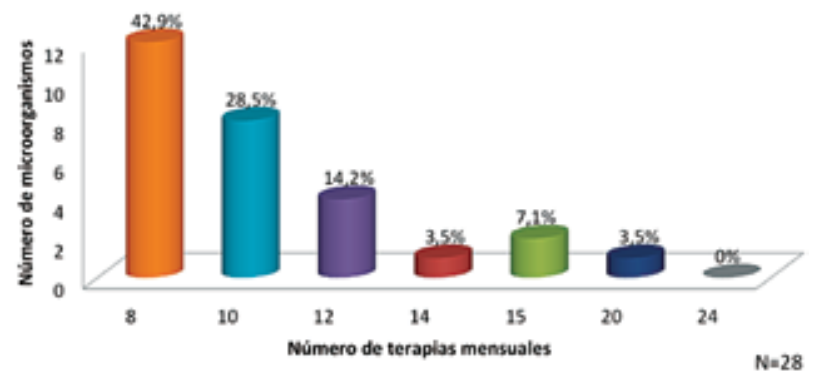

Al establecer la relación entre el número de terapias por mes de cada dispositivo con el número de microorganismos identificados, se encontró que en los dispositivos que tienen una frecuencia de uso de 8 terapias mensuales se identificó el $42,9 \%$, en los dispositivos con un uso mensual de 10 terapias correspondió al 28,5\% y con menores proporciones los dispositivos que tuvieron 12 terapias $14,2 \%, 14$ terapias 3,5\%, 15 terapias 7,1\%, 20 terapias $3,5 \%$ y 24 terapias con el $0 \%$ del total de microorganismos identificados.

Gráfica 9. Relación entre el modo de protección del dispositivo con el número de microorganismos identificados

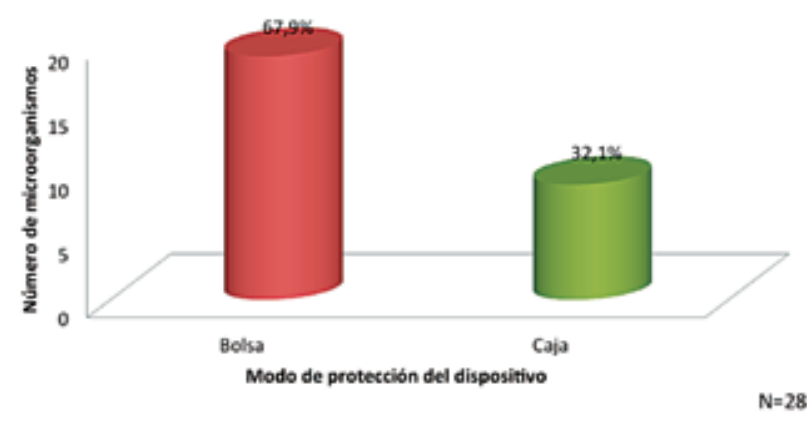

En relación al modo de protección del dispositivo frente al número de microorganismos identificados en el estudio, se encontró que del total de los microorganismos aislados, el 67,9\% corresponden a dispositivos que son preservados en bolsa plástica y el $32,1 \%$ a los que son guardados en caja plástica. 
De acuerdo a la indagación por encuesta sobre la aplicación del protocolo para la desinfección de los dispositivos por los terapeutas y los resultados en los aislamientos bacterianos se encontró que los dispositivos en los cuales se cumplió el protocolo estandarizado por Forja Empresas Ltda, para limpieza y desinfección antes y después del procedimiento de la terapia a los 15 y 30 días, no reportaron crecimiento bacteriano.

Tabla 1. Relación de cumplimiento del protocolo de limpieza y desinfección con el número de microorganismos identificados

\begin{tabular}{|c|c|c|c|c|}
\hline $\begin{array}{l}\text { Cód. del } \\
\text { paciente }\end{array}$ & Cód. del terapeuta & $\begin{array}{l}\text { Cumplimiento } \\
\text { *del protocolo }\end{array}$ & $\begin{array}{c}\text { Número de } \\
\text { microorganismos }\end{array}$ & Porcentaje \\
\hline 1 & 4 & $\mathrm{NO}$ & 2 & $7 \%$ \\
\hline 2 & 5 & $\mathrm{NO}$ & 2 & $7 \%$ \\
\hline 3 & 8 & $\mathrm{NO}$ & 4 & $17,8 \%$ \\
\hline 4 & 2 & SI & 0 & 0 \\
\hline 5 & 5 & $\mathrm{NO}$ & 3 & $10,6 \%$ \\
\hline 6 & 3 & $\mathrm{NO}$ & 1 & $3,5 \%$ \\
\hline 7 & 5 & $\mathrm{NO}$ & 1 & $3,5 \%$ \\
\hline 8 & 3 & $\mathrm{NO}$ & 2 & $7 \%$ \\
\hline 9 & 4 & $\mathrm{NO}$ & 2 & $7 \%$ \\
\hline 10 & 8 & $\mathrm{NO}$ & 3 & $10,6 \%$ \\
\hline 11 & 1 & $\mathrm{NO}$ & 1 & $3,5 \%$ \\
\hline 12 & 6 & $\mathrm{NO}$ & 2 & $7 \%$ \\
\hline 13 & 6 & $\mathrm{NO}$ & 2 & $7 \%$ \\
\hline 14 & 4 & $\mathrm{NO}$ & 1 & $3,5 \%$ \\
\hline 15 & 7 & $\mathrm{NO}$ & 1 & $3,5 \%$ \\
\hline 16 & 8 & $\mathrm{NO}$ & 1 & $3,5 \%$ \\
\hline 17 & 5 & SI & 0 & 0 \\
\hline
\end{tabular}

Los microorganismos aislados a partir de las muestras tomadas antes y después de la terapia fueron los siguientes: 
Tabla 2. Microorganismos aislados a partir de 17 dispositivos de micronebulización

\begin{tabular}{|c|c|c|}
\hline $\begin{array}{l}\text { Código asignado } \\
\text { para el paciente }\end{array}$ & Muestreo 15 días de uso & Muestreo 30 días de uso \\
\hline \multirow{2}{*}{1} & Antes. Pantoea agglomerans & Antes. Sin Crecimiento \\
\hline & Después. Sin Crecimiento & Después. Staphylococcus aureus \\
\hline \multirow{2}{*}{2} & Antes. Sin Crecimiento & Antes. Sin Crecimiento \\
\hline & Después. Streptococcus agalactiae & Después. Bacillus cereus \\
\hline \multirow{2}{*}{3} & Antes. Sin Crecimiento & Antes. Morganella sp. /Corynebacterium sp. \\
\hline & Después. Pseudomonas sp. & Después. Corynebacterium sp \\
\hline \multirow{2}{*}{4} & Antes. Sin Crecimiento & Antes. Sin Crecimiento \\
\hline & Después. Sin Crecimiento & Después. Sin Crecimiento \\
\hline \multirow{2}{*}{5} & Antes. Sin Crecimiento & Antes. Bacillus megaterium \\
\hline & Después. Sin Crecimiento & Después. Bacillus megaterium / Staphylococcus intermedius \\
\hline \multirow{2}{*}{6} & Antes. Enterobacter sakazakii & Antes. Sin Crecimiento \\
\hline & Después. Sin Crecimiento & Después. Sin Crecimiento \\
\hline \multirow{2}{*}{7} & Antes. Sin Crecimiento & Antes. Enterobacter sp. \\
\hline & Después. Sin Crecimiento & Después. Sin Crecimiento \\
\hline \multirow{2}{*}{8} & Antes. Sin Crecimiento & Antes. Bacillus brevis \\
\hline & Después. Sin Crecimiento & Después. Bacillus brevis \\
\hline \multirow{2}{*}{9} & Antes. Sin Crecimiento & Antes. Sin Crecimiento \\
\hline & Después. Bacillus megaterium & Después. Enterococcus faecium \\
\hline \multirow{2}{*}{10} & Antes. Sin Crecimiento & Antes. Candida lipolytica \\
\hline & Después. Enterobacter $s p$. & Después. Candida lipolytica \\
\hline \multirow{2}{*}{11} & Antes. Enterobacter sp. & Antes. Sin Crecimiento \\
\hline & Después. Sin Crecimiento & Después. Sin Crecimiento \\
\hline \multirow{2}{*}{12} & Antes. Micrococcus kristinae & Antes. Sin Crecimiento \\
\hline & Después. Sin Crecimiento & Después. Staphylococcus epidermidis \\
\hline \multirow{2}{*}{13} & Antes. Sin Crecimiento & Antes. Staphylococcus aureus \\
\hline & Después. Sin Crecimiento & Después. Staphylococcus aureus \\
\hline \multirow{2}{*}{14} & Antes. Sin Crecimiento & Antes. Staphylococcus epidermidis \\
\hline & Después. Sin Crecimiento & Después. Sin Crecimiento \\
\hline \multirow{2}{*}{15} & Antes. Enterobacter sp. & Antes. Sin Crecimiento \\
\hline & Después. Sin Crecimiento & Después. Sin Crecimiento \\
\hline \multirow{2}{*}{16} & Antes. Sin Crecimiento & Antes. Sin crecimiento \\
\hline & Después. Sin Crecimiento & Después. Staphylococcus saprophyticus \\
\hline \multirow{2}{*}{17} & Antes. Sin Crecimiento & Antes. Sin Crecimiento \\
\hline & Después. Sin Crecimiento & Después. Sin Crecimiento \\
\hline
\end{tabular}


Los microorganismos aislados en el estudio se clasificaron de acuerdo con los criterios de flora residente, flora transitoria y flora patógena, teniendo en cuenta que hacen parte de éstas.

Tabla 3. Clasificación de los microorganismos de acuerdo al tipo de flora.

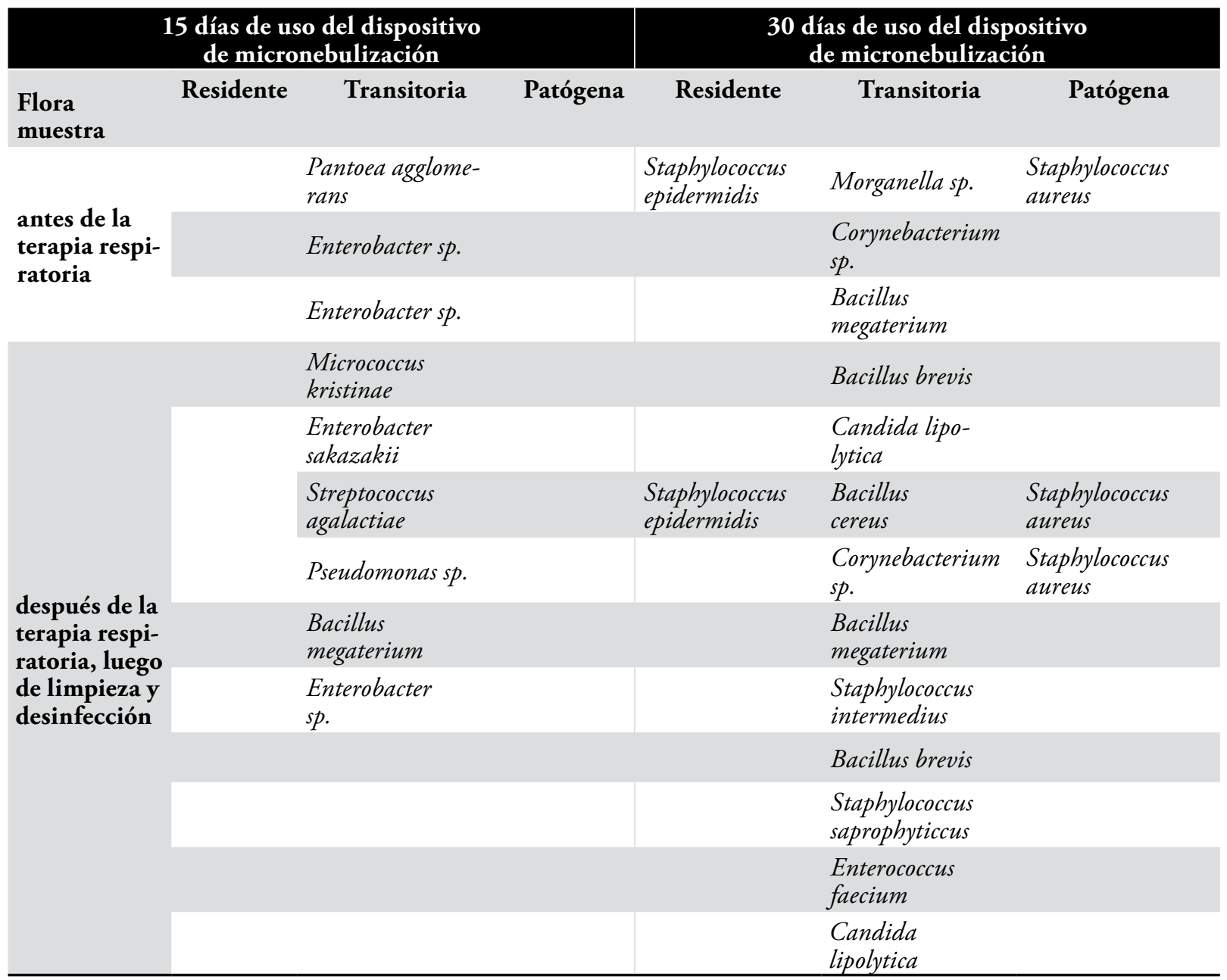

Los resultados obtenidos en el estudio demostraron que el $100 \%$ de los aislamientos realizados en la primera toma de muestra ( 15 días de uso), antes y después del uso del dispositivo correspondió a flora transitoria.

En la segunda toma de muestra (30 días de uso) antes del uso del dispositivos se obtuvo: que el $14,3 \%$ correspondió a flora residente, el $71,4 \%$ a flora transitoria y el $14,3 \%$ a flora patógena, mientras que después del uso del dispositivo se presentó aumento, flora patógena con $16,6 \%$, de flora transitoria con $75 \%$ y con mantenimiento de la flora residente $8,3 \%$.

\section{Discusión}

En el país hasta la fecha no se encuentran reportados en la literatura consultada investigaciones que aborden las variables y población objeto del presente estudio. Los resultados de la investigación estimulan la realización de nuevas investigaciones teniendo en cuenta un número mayor de muestras $y$ de variables.

Debido a la naturaleza de estar en un medio no controlado como lo son las residencias de los pacientes donde se realiza la terapia respiratoria, se tuvieron en cuenta solo las variables específicas que aplican a la presente investigación. 
La frecuencia de uso de los dispositivos de micronebulización en el estudio tienen un predominio de 8 a 10 terapias mensuales lo que representa el $64,7 \%$ del total de la población estudiada, frente a los dispositivos que tienen un uso superior a las 12 terapias mensuales que corresponden al 34,9\% del total, esto nos indica que el promedio de utilización de los dispositivos es de 2 ó 3 terapias por semana por paciente.

A través de la aplicación de encuestas y observación etnográfica se encontró que la mayoría de pacientes, familiares o/y cuidadores no conocen como funciona el dispositivo que poseen para la terapia respiratoria, situación que se podría asociar con la falta de cuidado en la protección del mismo, así como lo reportan estudios realizados en España y Brasil en los cuales consideran este aspecto como posible factor de riesgo en sobreinfección $(3,12)$.

En cuanto al instrumento aplicado a terapeutas frente al conocimiento y desarrollo del protocolo en la terapia respiratoria y según observación, se evidencia que para 6 de los terapeutas es común el conocimiento del protocolo de limpieza y desinfección de Forja Empresas Ltda, sin embargo solo el $25 \%$ hace cumplimiento de dicho protocolo, el otro $75 \%$ de los terapeutas han generado algún tipo de modificación en el procedimiento de éste, lo que conlleva a un inadecuado uso del dispositivo de micronebulización y al favorecimiento de contaminación.

Lo anterior podría estar vinculado a la presencia de microorganismos categorizados como flora transitoria, proveniente de diferentes fuentes como los guantes de látex y toallas de papel utilizadas por los terapeutas para secado del dispositivo, así como se concluye en investigaciones realizadas en el Hospital San Juan de Dios de Nicaragua, donde el aislamiento de Pseudomonas sp., Staphylococcus coagulasa negativa y Bacillus sp., provenientes de microbiota residente de piel o ambiente, se correlaciona con uso de guantes, ya que aunque estos son usados en un único procedimiento y con un único paciente, los guantes no son estériles y permanecen puestos antes, durante y después del procedimiento, además las bolsas y en ocasiones los recipientes de guardado para el dispositivo de micronebulización una vez usado no son estériles, aspecto que también podría estar relacionado con contaminación (4).

El $100 \%$ de los terapeutas realiza lavado de manos antes del procedimiento, sin embargo todos los profesionales no lo realizan de la misma forma, depende de los elementos con que cuenten en cada casa, de la disponibilidad para el uso de guantes y de exigencias particulares por los familiares de los pacientes.

De otro lado se observa que el protocolo estandarizado por FORJA EMPRESAS LTDA. para la limpieza y desinfección de los dispositivos, no incluye en la etapa inicial del proceso el detalle en el lavado de manos. Al respecto la Organización Mundial de la Salud (OMS) en "WHO Guidelineson Hand Hygiene in HealthCare" presenta una recopilación de evidencia científica acerca de la transmisión de patógenos a través de las manos del personal de salud a los pacientes, lo cual puede ocurrir cuando se hayan microorganismos en la piel del paciente, que son transferidos a superficies bióticas y abióticas (tendidos de cama, ropa, utensilios y muebles) mediante contacto directo con el paciente y donde la antisepsia de las manos por parte del terapeuta es un factor determinante para la adquisición de patógenos (13).

De acuerdo con lo anterior, es probable que la mayoría de flora transitoria y potencialmente patógena identificada en este estudio provenga de la transmisión indirecta producto de la interacción del terapeuta con diferentes fuentes de microorganismos.

En cuanto a la relación del tiempo de uso de los dispositivos con el número de microorganismos identificados en cada uno de los momentos de la toma de muestra, se evidencia aumento en la 
segunda toma de muestra con respecto a la prime$\mathrm{ra}$, encontrando que en la primera toma se presenta un mayor aislamiento antes del uso del dispositivo en la terapia que después de su uso; opuesto a lo que sucede en la segunda toma donde se aislaron más microorganismos después del uso del dispositivo que antes del procedimiento.

Sin embargo, es importante recalcar que en el $11,8 \%$ del total de los dispositivos no se aislaron microorganismos, lo que puede estar directamente relacionado con el adecuado proceso de limpieza y desinfección del dispositivo, como se observa en la tabla 2, relacionada con la aplicación del protocolo de limpieza y desinfección por parte de los terapeutas. Al respecto los resultados del estudio realizado en el hospital de Curitiva (Brasil) en los dispositivos usado por pacientes con fibrosis quística a pesar de que se aislaron microorganismos como Klebsiella pneumoniae, Staphylococcus coagulasa negativa, Bacillus sp., Pseudomonas aeruginosa, Staphylococcus aureus y levaduras, también se encontró en este estudio que algunos de los participantes que tenían dispositivos de nebulización con tiempo de uso hasta de un ańo, el tiempo no fue un factor de riesgo para presentar sobreinfección, aunque sí se pudo observar una disminución en la eficiencia terapéutica de las nebulizaciones (3).

Al relacionar el número de terapias respiratorias mensuales con el número de microorganismos aislados durante las terapias, se observó que a menor número de terapias, (de 8 a 10 terapias mensuales) se presenta un mayor número de microorganismos, esto se puede deber a que el dispositivo al permanecer guardado por periodos de tiempo más largos favorece el desarrollo de los microorganismos cuando hay contaminación en el equipo, contrario a los dispositivos que tienen un uso de más de 12 terapias, en los cuales se evidenció que el aislamiento microbiano es menor o ninguno.

Con relación al uso de bolsa como tipo de protección y almacenamiento más frecuentemente utilizado por los usuarios de los dispositivos (el 70,5\% del total de dispositivos), se observa que por sus características la bolsa plástica, crea un ambiente húmedo que favorece el desarrollo de algunos microorganismos, como es el caso de la levadura Candida lypolitica y especies de algunas bacterias como las del género Bacillus y Corynebacterium y otras especies bacterianas como lo reporta la literatura microbiológica $(14,15)$, por lo que se sugiere, usar caja plástica de cierre hermético, ya que por su estructura y tipo de cierre facilita el proceso de limpieza y desinfección y mantiene el dispositivo libre de contaminación ambiental.

Otro factor, que puede afectar el uso adecuado de los dispositivos de micronebulización, es el incumplimiento del protocolo de limpieza y desinfección, al respecto se observó que en los dispositivos en los cuales los terapeutas no lo aplicaron o en su defecto introdujeron modificaciones de acuerdo al criterio propio, se obtuvo un mayor número de aislamientos con respecto a los dispositivos en los cuales los terapeutas aplicaron el protocolo de manera correcta.

En general la flora bacteriana encontrada en este estudio, guarda similitud a la encontrada por Gaetti et al (5), en nebulizadores de uso hospitalario y domiciliario, quienes reportan mayor presencia de Staphylococcus sp, seguido de Pseudomonas aeruginosa, Morganella morganni, Enterococcus faecium, Staphylococcus epidermidis y Staphylococcus saprophyticus. De igual forma Gaetti y colaboradores obtienen como resultado que al lavar el dispositivo con agua y jabón únicamente, hay mayor presencia de bacterias Gram negativas, si bien en el presente estudio no se aislaron con alta frecuencia este tipo de bacterias, si podría ser un indicador de marcada deficiencia en el proceso de lavado.

Teniendo en cuenta que en la primera toma de muestra se aislaron microorganismos de flora transitoria y la flora residente y patógena apareció en el estudio en la segunda toma de muestra, se requiere explicar el riesgo que cada uno de estos microorganismos representa para el paciente: 
Enterobacter sp, se encuentra en verduras, suelo y aguas cloacales, se reporta en infecciones oportunistas que afectan al sistema respiratorio y urinario. Enterobacter sakazakii se asocia a meningitis, abscesos cerebrales, enterocolitis necrosante y sepsis en neonatos (15). Este microorganismo es similar a Pantoea agglomerans, tratado en algunos casos como contaminante ambiental que pertenecía al género Enterobacter (17).

Pantoea agglomerans, proviene de gran diversidad de fuentes ecológicas y geográficas. Las infecciones por este agente causal en pacientes inmunocomprometidos presentan sintomatología respiratoria similar a la de una tuberculosis (19).

Pseudomonas sp., pueden ser parte de la flora normal faríngea, otras son patógenas y agentes causales de infecciones nosocomiales, sepsis y bacteriemias a partir de dispositivos médicos como catéteres. El género se categorizó como flora transitoria debido a que varias especies se han aislado de esputo, orina, oído, heridas y equipos para terapia inhalatoria, especialmente en pacientes inmunosuprimidos (15). Las bacterias pertenecientes al género Morganella sp, se relacionan con infecciones urinarias y diarreas, siendo causa importante de infecciones nosocomiales (17).

Con respecto al género Bacillus, pocas de las especies pertenecientes al género se consideran patógenas, sin embargo, debido a la manipulación y creciente resistencia bacteriana se pueden considerar oportunistas $(19,20)$, pueden ser considerados flora transitoria contaminantes de piel y mucosas o estar presente en el ambiente, al igual que $\mathrm{Mi}$ crococcus kristinae, el cual se ha reportado en neumonía, sepsis, bacteriemia, meningitis, colecistitis, endocarditis asociada a válvula nativa, entre otras infecciones (21).

Especies del género Corynebacterium sp., son agentes causales de diferentes infecciones en sistema respiratorio, además se ha aislado en casos de sepsis, bacteriemias e infecciones urinarias agudas y crónicas en pacientes inmunocomprometidos, aunque ocasionalmente son flora normal de piel (15).

La única estructura fúngica aislada fue Candida lipolytica, levadura que se ha descrito como patógeno poco frecuente de escasa virulencia, en raras ocasiones se encuentra como flora de boca y tracto respiratorio, se relaciona con fungemia en pacientes con enfermedades hematológicas de base, enfermedades crónicas, sondaje vesical y uso de catéteres (22).

Enterococcus faecium presenta alta resistencia a antibióticos, se encuentra como flora normal en el tubo digestivo y vías biliares de humanos y de algunos animales. Se aísla de muestras de importancia clínica en humanos causando frecuentemente infecciones urinarias y bacteriemias relacionadas con factores de riesgo como inmunosupresión e implantación de instrumentación urinaria, respiratoria y otros dispositivos biomédicos. Además ocasiona infecciones graves en piel, tejidos blandos, heridas quirúrgicas y procesos infecciosos intraabdominales. En adultos mayores se han reportado en graves fístulas biliobronquiales $(15,23)$.

Staphylococcus saprophyticcus, en los últimos años ha sido recuperado como agente etiológico de neumonía a nivel hospitalario (15). En estudios de fármaco-vigilancia intrahospitalaria se ha reportado alrededor de un $9 \%$ en esputo de niños con afecciones respiratorias, algunas cepas tienen genes de resistencia bacteriana, además de considerarse agente causal de neumonía asociada a ventilador mecánico $(24,25)$.

Staphylococcus epidermidis puede estar asociado a infecciones subagudas, siendo causa de sepsis en pacientes con neutropenia e inmunosupresión, causa con frecuencia infecciones asociadas a catéteres y válvulas, ya que sus macromoléculas favorecen la adhesión a los plásticos de los dispositivos biomédicos, con formación de biopelículas, además se ha identificado en 
bacteriemias de pacientes con inmunosupresiones de origen diverso, infecciones de injerto vascular e infecciones oftálmicas. La mayor parte de estas infecciones están relacionadas a la estancia hospitalaria y migración del microorganismo a sitios anatómicos normalmente estériles (15). La sepsis y endocarditis se ha relacionado a la infección por translocación de la mucosa intestinal al torrente sanguíneo en pacientes con trastornos linfoproliferativos (26).

Staphylococcus aureus se considera flora potencialmente patógena, ya que todos los pacientes del estudio se encuentran en estado de inmunosupresión y es frecuente agente causal de neumonías en este grupo etario, se vinculó posiblemente, como se ha mencionado a procedimientos ineficientes de limpieza y desinfección, o colonización nasal del microorganismo en el paciente. Como agente causal de infecciones respiratorias puede originarse por aspiración o migración del microorganismo por vía hematógena. Se asocia con neumonía adquirida en la comunidad, frecuente en ancianos ligada en algunos casos, a complicaciones relacionadas a virus de la influenza (15).

En el estudio realizado por Rodríguez et al. (12) en adultos mayores espańoles que hacen uso de dispositivos de nebulización, se encontró en la mayoría de los aislamientos Staphylococcus aureus, el cual se relacionó con el proceso de limpieza y desinfección incorrectos, resultado que es similar en el presente estudio.

La Guía de práctica clínica colombiana: "recomendaciones para neumonía adquirida en la comunidad en adultos inmunocompetentes", considera relevante este microorganismo puesto que se reportan cepas con resistencia a meticilina las cuales se asocian con neumonía necrosante. Por otro lado en adultos mayores de 65 ańos es agente causal del 3,5\% de los casos de neumonía en el país, por lo cual se plantea la necesidad de aumentar las estrategias de vigilancia a partir de los hallazgos para los usuarios de esta modalidad de atención (27).

\section{Agradecimientos}

Especial agradecimiento a Forja Empresas Ltda, prestadora de servicios de atención de salud a domicilio, a los pacientes y terapeutas del programa hospitalización en casa.

\section{Referencias}

1. Sociedad Española de Neumología y Cirugía Torácica SEPAR. Recomendaciones para la Prevención y Control de las Infecciones Asociadas a la Asistencia en el Medio Extrahospitalario. $1^{\text {a }}$ edición. Valencia: Editorial Generalitat Valenciana; 2006.

2. Sociedad Española de Neumología y Cirugía Torácica SEPAR. Manual de Atención domiciliaria del paciente con Enfermedad Pulmonar Obstructiva Crónica (EPOC).2a edición. Barcelona: Editorial SEPAR; 2011.

3. Costa L, Riedi C, Kussek P; Homem H; Rosário N. Nebulizadores: Fonte de contaminação Bacteriana em Pacientes com Fibrose Cística?. Scielo [base de datos en internet]. Curitiba: Jornal Brasileiro de Pneumologia; 2011. [fecha de acceso 14 de enero de 2013]. Disponible en: http://www.scielo.br/scielo. php?script=sci_arttext\&pid=S1806-37132011000300010

4. Lima L. Determinación de Posibles Fuentes de Infección Nosocomial en Unidades de Cuidados Intensivos Pediátricos del Hospital General San Juan de Dios. Managua: Universidad San Carlos de Guatemala; 2004. [acceso 4 de agosto de 2012]. Disponible en: http://biblioteca.usac.edu.gt/ tesis/06/06_2250.pdf

5. Gaetti E, Schweitzer C, Gomes A, Oliveira K, Sangalli J, et al. Nebulizadores e a Possibilidade de Transmissão de Microrganismos Superinfectantes e Oportunistas. Revista Brasileira de Ciências da Saúde [revista en Internet] 2009 [acceso 6 de septiembre de 2012]; 13 (2). Disponible en: http://periodicos. ufpb.br/ojs2/index.php/rbcs/article/view/3259

6. Cifuentes Y, Robayo C, Ostos O, Muñoz L, Hernández R. Neumonía Asociada a la Ventilación Mecánica: Un Problema de Salud Pública. Revista colombiana de Ciencias Químico Farmacéuticas [revista en Internet] 2008 [acceso 6 de septiembre de 2012]; 37 (2): [150-153]. Disponible en: http:// www.revistas.unal.edu.co/index.php/rccquifa/article/viewFile/15244/16040

7. Asociación Colombiana de Infectología. Guías de Práctica Clínica para la Prevención de Infecciones Intrahospitalarias Asociadas al Uso de Dispositivos Médicos. Revista Infectio [revista en Internet] 2010 [acceso 6 de septiembre de 2012]; 14 (4). Disponible en: http://revistainfectio.org/site/portals/0/ojs/index.php/infectio/article/view/69

8. Departamento Administrativo Nacional de Estadística. Censo general 2005. [acceso 22 de Agosto de 2012] Disponible en: http:// www.dane.gov.co/censo/files/libroCenso2005nacional.pdf.

9. Espinel M, Sánchez S, Juárez T, García J, Viveros A, García. Impacto de un programa de atención domiciliaria al enfermo crónico en ancianos: calidad de vida y reingresos hospitalarios. Scielo [base de datos en internet]. Cuernavaca: Salud pública de México; 2011. [acceso 14 de enero de 2013]. Disponible en: http://www.scielo.org.mx/scielo.php?script=sci_arttext\&p $\mathrm{id}=$ S0036-36342011000100004 
10. Gamboa G. Atención Domiciliaria de la Persona Anciana: Una Perspectiva Bioética. Revista AQUICHAN [revista en Internet] 2009 [fecha de acceso 14 de enero de 2013]; 9 (2): [171182]. Disponible en: http://aquichan.unisabana.edu.co/index. php/aquichan/article/view/1480/1648

11. Secretaría Distrital de Salud de Bogotá, D. C. Manual para la toma de muestras para análisis microbiológico. $1^{a}$ edición. Bogotá D.C: Linotipia Bolívar y Cía. S. en C; 2008.

12. Rodríguez J, Andrade G, Díeza J, López M, Sánchez C, Izquierdo L, et al. Colonización Bacteriana y Ventilación Mecánica Domiciliaria. Prevalencia y Factores de Riesgo. ArchBronconeumol [revista en Internet] 2004 [acceso 6 de septiembre de 2012]; 40 (9). Disponible en:http://apps.elsevier.es/watermark/ ctl_servlet?_f=10\&pident_articulo=13065172\&pident_ usuario $=0 \&$ pcontactid $=\&$ pident_revista $=6 \&$ ty $=88 \&$ accion $=$ L\&origen=bronco\&web=http://www.archbronconeumol.org \&lan=es\&fichero=6v40n09a13065172pdf001.pdf

13. World Health Organization. Guidelines on Hand Hygiene in Health Care. First Global Patient Safety Challenge Clean Care is Safer Care. 2a Edicion. Switzerland: WHO; 2009.

14. Borrego S, Pons V, Perdomo I. La contaminación microbiana del aire en dos depósitos del Archivo Nacional de la República de Cuba. Revista CENIC Ciencias Biológicas [revista en Internet] 2008 [acceso 3 de mayo de 2012]; 39 (1). Disponible: http://revistas.unlp.edu.ar/domus/article/viewFile/97/117

15. Allen, Janda, Koneman, et al. Diagnóstico microbiológico. Texto y Atlas a color. 6a Edición. Buenos Aires: Editorial Médica Panamericana; 2008

16. Vanegas M, Rugeles L, Martínez A. Aislamiento e identificación de Enterobacter sakazakii en lactarios de Bogotá, D. C. Revista Infectio. [revista en Internet] 2009 [acceso 6 de junio de 2013]; 13 (1). Disponible en: http://revistainfectio.org/site/ portals/0/ojs/index.php/infectio/article/view/72

17. Flores E, Miranda M, et al. Pantoea agglomerans in Immunodeficient Patients with Different Respiratory Symptoms. Pubmed [base de datos en internet]. Mexico: The Scientific World Journal; 2012 [acceso 6 de junio de 2013].Disponible en: http://www.ncbi.nlm.nih.gov/pmc/articles/PMC3349103/ pdf/TSWJ2012-156827.pdf

18. Zalas-Więcek P, Michalska A, et al. Morganella sp. rods--characteristics, infections, mechanisms of resistance to antibiotics. Pubmed [base de datos en internet]. PostepyHig Med Dosw; 2012 [acceso 6 de junio de 2013]. Disponible en: http://www. ncbi.nlm.nih.gov/pubmed/22706110

19. P.M. Periago. B. megaterium Spore Germination and Growth Inhibition, Food Technol. Revista Biotechnol [revista en Internet] 2006 [acceso 6 de junio de 2013]; 44 (1): [17-23]. Disponible en: http://hrcak.srce.hr/file/161701\&prev=/search\%3 Fq\%3DB.\%2Bmegaterium\%2BSpore\%2BGermination\%2B and\%2BGrowth\%2BInhibition,\%2BFood\%2BTechnol.\%26 espv\%3D210\%26es_sm\%3D93
20. Hutchens A, Gupte A. Bacillus cereus Necrotizing Fasciitis in a Patient with End-Stage Liver Disease Surgical Infections. Pubmed [base de datos en internet] Florida: Surg infect; 2010. [acceso 4 de junio de 2013]. Disponible en: http://www.ncbi. nlm.nih.gov/pubmed/20649455

21. Seyman D, Kizilates F, et al. Kocuria kristinae: A Rare Cause of Infective Endocarditis Involving 2 Native Valves. Infectious Diseases in ClinicalPractice [revista en Internet] 2013 [acceso 13 de noviembre de 2013]; 21 (6) Disponible en: http:// journals.lww.com/infectdis/Abstract/2013/11000/Kocuria_ kristinae_A_Rare_Cause_of_Infective.17.aspx

22. Blanco M, García P. Fungemia por Candida lipolytica: a propósito de 2 casos. Revista Iberoamericana de Micología. [revista en Internet] 2009 [acceso 4 de junio de 2013]; 26 (3). Disponible en: http://zl.elsevier.es/es/revista/revista-iberoamericana-micologia-290/fungemia-candida-lipolytica-proposito2-casos-13140455-notas-2009

23. Martínez E, Palomar L, Olivo J. Fistula Bilobronquial. Scielo [base de datos en internet]. Zamora: Revista Española de Enfermedades Digestivas; 2012. [acceso 4 de junio de 2013]. Disponible en: http://scielo.isciii.es/scielo.php?pid=S1130$01082012000400007 \&$ script=sci_arttext $\&$ tlng=es

24. Fang Min,HeQiuning. Analysis of 217 Strains Bacteria and their Drug Susceptibility from Hospitalized Children with Lower Respiratory Tract Infections. Pubmed [base de datos en internet]. Journal of Pediatric Pharmacy; 2012. [acceso 4 de junio de 2013]. Disponible en: http://en.cnki.com.cn/Article_en/CJFDTOTAL-EKYX201205014.htm

25. Kazem M, Abolfazl S. Surveillance of Ventilator Associated Pneumonia in Neonatal Intensive Care Unit: Characteristics, Risk Factors, and Outcome. Pubmed [base de datos en internet]. IArchives of Iranian Medicine; 2012. [acceso 4 de junio de 2013]. Disponible en: http://www.ncbi.nlm.nih.gov/pub$\mathrm{med} / 22924377$

26. Muldrew K, Tang Y, Li H, Stratton C. Clonal Dissemination of Staphylococcus epidermidis in an Oncology Ward. Pubmed [base de datos en internet]. Journal of Clinical Microbiology; 2008 [acceso 4 de junio de 2013]. Disponible en: http://www. ncbi.nlm.nih.gov/pmc/articles/PMC2566116/

27. Asociación Colombiana de Infectología. Recomendaciones para el diagnóstico, tratamiento y prevención de la neumonía adquirida en la comunidad en adultos inmunocompetentes. Guía de Práctica Clínica. Revista Infectio [revista en Internet] 2013 [acceso 15 de agosto de 2013]; 17 (1). Disponible en: http://revistainfectio.org/site/portals/0/ojs/index.php/infectio/article/view/588 
